\title{
Rapidly progressing cataract after microwave exposure
}

\begin{abstract}
A young engineer developed bilateral cataract few days after exposure to high microwave energy while working on a radar platform. The cataract progressed rapidly and this was documented by anterior segment photos. The primary damage mechanism of microwave radiation is thermal, by dielectric heating. Non-thermal effects are less understood. Cataract formation after microwave exposure has been proven in experimental animal eyes and reported in isolate not well documented cases. The timeframe of cataract onset after exposure to the radar high microwave energy and the very unusual rapid progression of this cataract raise the odds of a causative relationship.
\end{abstract}

Keywords: microwave energy, cataract, thermal damage, rapid progression, anterior segment photography
Volume 2 Issue I - 2015

\author{
Shucri Shawaf \\ Sharif Eye Center, UAE
}

Correspondence: Shucri Shawaf, Sharif Eye Center, Dubai Healthcare City, Bldg 27, Block D, Suite I0I, Dubai UAE, Tel 97|5078|86|3,Email ssshawwaf@gmail.com

Received: December 0I, 2014 | Published: January 14,2015

\section{Abbreviations: RE, right eye; LE, left eye; BE, both eyes}

\section{Introduction}

To report a case of rapidly progressing bilateral cataract days after exposure to high microwave energy

Case presentation: A 39year old male engineer was exposed to high microwave energy when the power of the military radar was switched on while he was doing maintenance work on its platform. He presented to me 3days after this exposure complaining of difficulty in reading of acute onset. Exam was unremarkable including unaided vision of 1.0 in each eye for distance and clear lenses. Refraction showed emmetropia in both eyes (BE). He was prescribed +1.0 readers and reassured as a case of relatively early onset presbyopia. He returned 1week later with unaided vision of 1.0 blurred in the right eye (RE) and 0.3 in the left eye (LE). Auto refraction revealed emmetropia RE and-18.00 in the LE. Exam revealed anterior and posterior subcapsular precipitates, peripheral in RE, but reaching the center in LE. On weekly successive visits his vision continued to drop LE more than RE and progression of his cataract could be clearly documented with anterior segment photography. Three weeks after his initial visit, vision dropped to $0.8 \mathrm{RE}$ and $0.05 \mathrm{LE}$. Optical coherence tomography was performed and showed no macular pathology with foveal thickness RE 271 and LE $272 \mathrm{um}$. He underwent phaco emulsification with intraocular lens implantation BE in his home country and returned to me to continue his follow-up. Uncorrected visual acuity was 1.0BE. Three months post-operatively he developed severe macular edema and his vision dropped to $0.3 \mathrm{BE}$. His macular edema resolved with topical nepafenac $0.1 \%$ with unaided visual acuity of $1.0 \mathrm{BE}$.

\section{Discussion}

The increasing applications of microwaves, mainly in mobile phones and radar, induce a higher rate of exposed people, sometimes cause of worry. ${ }^{1}$ In comparison with burns caused by ionizing radiation, where tissue damage is due to internal cell damage caused by free radicals, the primary damage mechanism of microwave radiation is thermal, by dielectric heating. ${ }^{2}$ Lower frequencies penetrate deeper into tissues, ${ }^{3}$ and as there are only few nerve endings in deeper tissues, the damage caused by the radio frequency waves may not be immediately noticeable. The lower frequencies at high power densities present a significant risk. The human body acts as a broadband antenna. ${ }^{4}$ The microwave absorption is directed by the dielectric constant of the tissue ${ }^{3,5}$ (Figures 1-3).

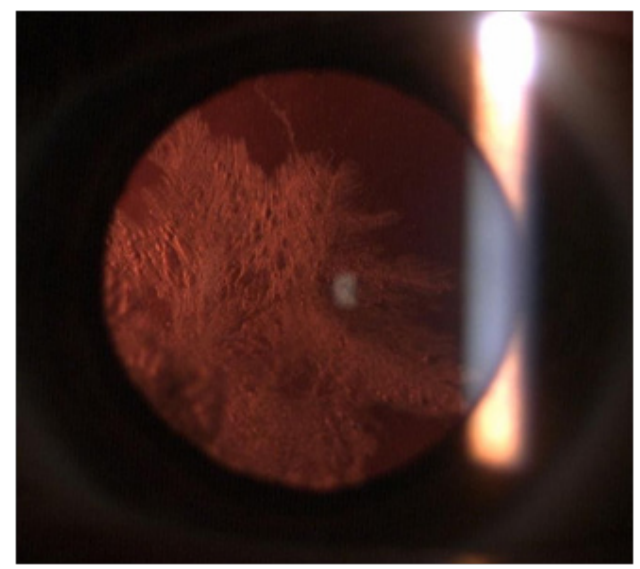

Figure I LE cataract IOdays after exposure.

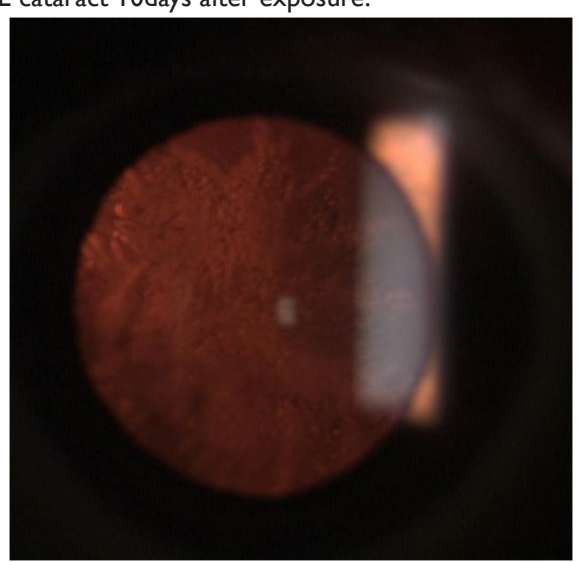

Figure 2 LE cataract I7days after exposure. 


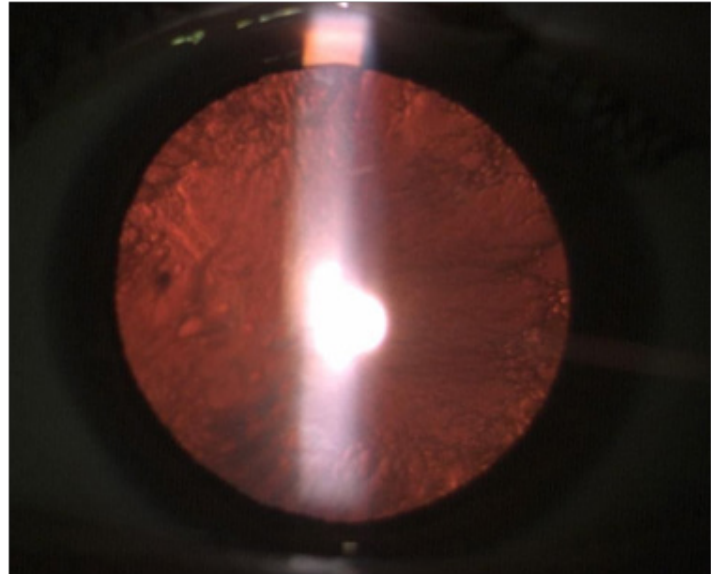

Figure 3 LE cataract 24days after exposure.

The tissue damage depends primarily on the absorbed energy and the tissue sensitivity. It is a function of the microwave power density (which depends on the distance from the source and its power output), frequency, absorption rate in the given tissue, and the tissue sensitivity. Tissues with high water content show higher microwave absorption. The degree of the tissue damage depends on both the achieved temperature and the length of exposure. ${ }^{2}$

There are also non-thermal effects of microwave energy on the eye including pressure waves and physical stretching, deformation, and tearing of the membranes of the lens cells. ${ }^{1,6}$ Some experiments on rabbits and dogs showed that the ocular effects are confined to eyelids, conjunctiva and anterior segment (keratitis or iritis), ${ }^{3}$ others proved induced cataracts in rabbits,,${ }^{7,8}$ rats, ${ }^{9}$ pig eyes ${ }^{10,11}$ and murine ocular lens in vitro ${ }^{12}$ but not in monkeys. ${ }^{8}$ A group from Amsterdam developed a reproducible cataract model for phaco-training purposes where cataract was induced in postmortem pig eyes after 9seconds in a microwave oven. ${ }^{11}$ Non-thermal cellular effects of low power microwave radiation include loss of lens transparency, alteration of cell proliferation and apoptosis, inhibition of gap junctional intercellular communication, and genetic instability. ${ }^{6}$ Modern radars using directional antennas can deliver pulse power densities many times higher than those employed in these experiments. ${ }^{12}$ Cases of severe conjunctivitis were reported after technicians looked into powered waveguides. ${ }^{5}$

Microwave-induced cataracts in humans are reported in scattered and isolated partially documented cases. Cataracts were observed in several workers exposed to radiofrequency radiation. ${ }^{13}$ Some sources however mention incidence of microwave-related injuries of ocular lens and retina. ${ }^{14}$ Microwave energy has been added to the armamentarium of keratoconus treatment. ${ }^{15,16}$

The interesting aspect in our case was the documentation by anterior segment photography of the rapid progression of cataract formation in a presumably healthy young patient with no apparent risk factors predisposing him to early onset cataract. The timeframe of cataract onset after exposure to the radar high microwave energy and the very unusual rapid progression of this cataract raise the odds of a causative relationship.

\section{Acknowledgements}

None.

\section{Conflict of interest}

The author declares no conflict of interest.

\section{References}

1. Vignal R, Crouzier D, Dabouis V, et al. Effects of mobile phones and radar radiofrequencies on the eye. Pathol Biol (Paris). 2009;57(6):503-508.

2. Ronald Kitchen. RF and Microwave Radiation Safety Handbook. 2nd ed. Linacre House, Jordan hill, Oxford OX2 8DP, 225 Wildwood Avenue, Worborn, MA 01801-2041. A member of the reed Elsevier group. A division of reed educational and professional publishing Ltd. ButterworthHeinemann; 2001. 60 p.

3. Barnes FS, Greenebaum B. Biological and medical aspects of electromagnetic fields. Handbook of Biological Effects of Electromagnetic Fields. 3rd ed. CRC Press, Taylor \& Francis Group; 2006. 342 p.

4. John B, Sullivan Jr, Gary R, et al. Clinical Environmental Health and Toxic Exposures. 2nd ed. 530 Walnut Street. Philadelphia, PA 19106 USA: Lippincott Williams \& Wilkins; 2001. p 205-206.

5. Hitchcock RT, Patterson RM. Radio-Frequency and ELF Electromagnetic Energies: A Handbook for Health Professionals. 605 Third Avenue, NY 10158-0012. New York: John Wiley \& Sons, Inc; 1995. p. 178-183.

6. Yu Y, Yao K. Non-thermal cellular effects of low power microwave radiation on the lens and lens epithelial cells. J Int Med Res. 2010;38(3):729-736.

7. Lipman RM, Tripathi BJ, Tripathi RC. Cataracts induced by microwave and ionizing radiation. Surv Ophthalmol. 1988;33(3):200-210.

8. Elder JA. Ocular effects of radiofrequency energy. Bioelectromagnetics. 2003;6:S148-161.

9. Trevithick JR, Creighton MO, Sanwal M, et al. In Vitro studies of microwave-induced cataract III: In Vitro lenticular effect enhancement by L-band-pulsed vs. Continued wave microwave irradiation of rat lens. Scanning Microscopy. 1998;12(4):609-629.

10. Shentu X, Tang X, Ye $\mathrm{P}$, et al. Combined microwave energy and fixative agent for cataract induction in pig eyes. J Cataract Refract Surg. 2009;35(7):1150-1155.

11. van Vreeswijk H, Pameyer JH. Inducing cataract in postmortem pig eyes for cataract surgery training purposes. $J$ Cataract Refract Surg. 1998;24(1):17-18

12. Stewart-DeHaan PJ, Creighton MO, Larsen LE, et.al. In vitro studies of microwave-induced cataract: Separation of field and heating effects. Experimental Eye Research. 1983;36(1):75-90.

13. Lin JC. Advances in electromagnetic fields in living systems. Vol 2. A division of Plenum Publishing Corporation. N. Y. 10013. Plenum Press, New York: 233 Spring street; 1997. 155 p.

14. Palmer KT, Cox RAF, Brown I. Fitness for Work. The Medical Aspects. 4th ed. Occup Environ Med. 2007;64(11):786.

15. Vega-Estrada A, Alio JL, Plaza Puche AB, et al. Outcomes of a new microwave procedure followed by accelerated cross-linking for the treatment of keratoconus: a pilot study. J Refract Surg. 2012;28(11):787793.

16. Celik U, Alagoz N, Yildirim Y, et al. New method of microwave thermokeratoplasty to correct myopia in 33 eyes: one-year results. $J$ Cataract Refract Surg. 2013;39(2):225-233. 